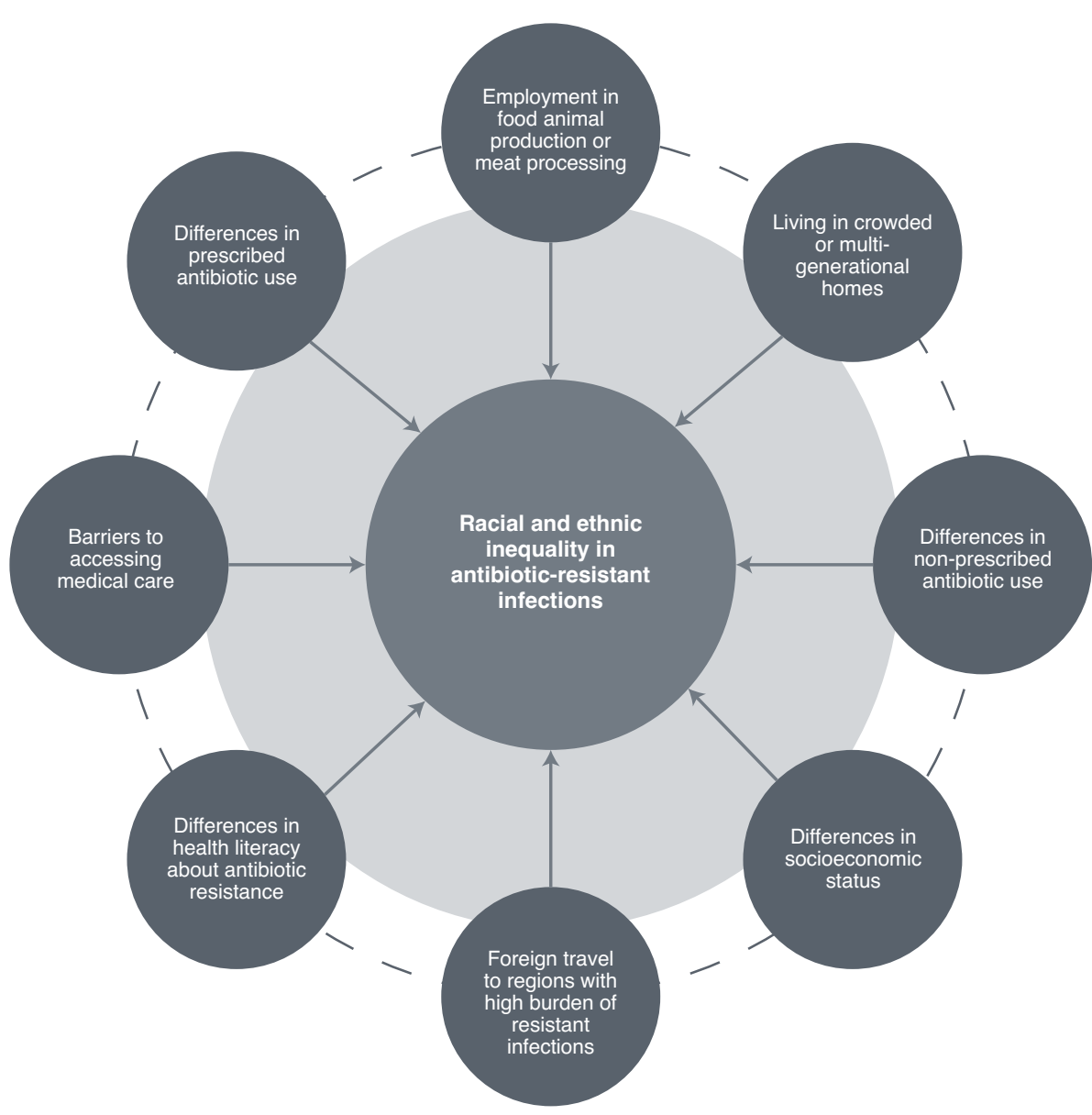

Fig. 1 | Factors that may contribute to racial and ethnic inequality in antibiotic resistance-related morbidity and mortality.

have a low income or are undocumented or uninsured or reside in crowded urban areas may be at risk regardless of their race or ethnicity. Consequently, efforts that seek to improve living conditions, economic stability, education, and access to healthcare in medically underserved areas could drastically slow the AR pandemic. Fourth, we must recognize that disparities in $\mathrm{AR}$ may be driven by global changes. Dietary shifts, increases in urbanization, widening income inequality and global warming could exacerbate disparities across the globe. Finally, we the authors encourage all readers to personally acknowledge and address their own racial and ethnic biases. Given the role of implicit bias on clinical decision-making, it is crucial to critically evaluate and work toward dismantling bias, holding both ourselves and other healthcare professionals accountable for our attitudes and behaviors. A proactive approach that aims to understand, characterize and address the factors that contribute to racial and ethnic inequality in AR has the power not only to inform and guide our response to the next pandemic but also to prevent AR from becoming the next epidemic of inequality.

\section{Maya L. Nadimpalli1,2四, Courtney W. Chan ${ }^{3}$ and Shira Doron ${ }^{2,3}$ \\ ${ }^{1}$ Department of Civil and Environmental Engineering, Tufts University, Medford, MA, USA. ${ }^{2}$ Stuart B. Levy Center for Integrated Management of Antimicrobial Resistance, Tufts University, Boston, MA, USA. ${ }^{3}$ Division of Geographic Medicine and Infectious Diseases, Tufts Medical Center, Tufts University School of Medicine, Boston, MA, USA. $\bigotimes_{e-m a i l: m a y a . n a d i m p a l l i @ t u f t s . e d u}$}

Published online: 18 January 2021 https://doi.org/10.1038/s41591-020-01201-9

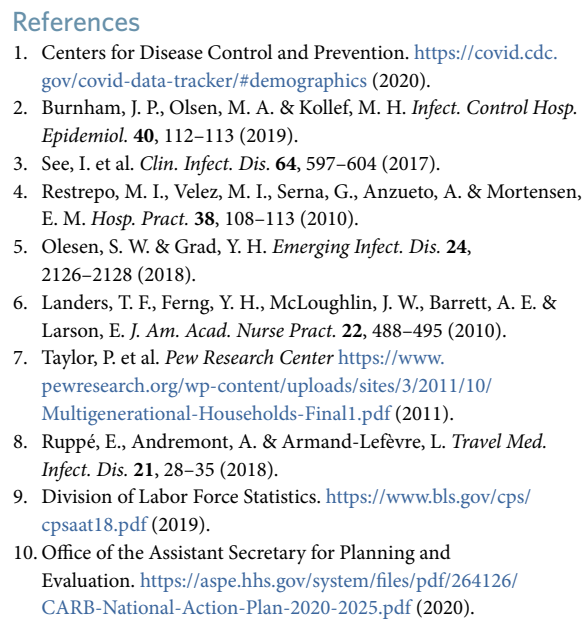

1. Centers for Disease Control and Prevention. https://covid.cdc. gov/covid-data-tracker/\#demographics (2020).

2. Burnham, J. P., Olsen, M. A. \& Kollef, M. H. Infect. Control Hosp. Epidemiol. 40, 112-113 (2019).

3. See, I. et al. Clin. Infect. Dis. 64, 597-604 (2017).

4. Restrepo, M. I., Velez, M. I., Serna, G., Anzueto, A. \& Mortensen, E. M. Hosp. Pract. 38, 108-113 (2010).

5. Olesen, S. W. \& Grad, Y. H. Emerging Infect. Dis. 24 2126-2128 (2018)

6. Landers, T. F., Ferng, Y. H., McLoughlin, J. W., Barrett, A. E. \& Larson, E. J. Am. Acad. Nurse Pract. 22, 488-495 (2010).

7. Taylor, P. et al. Pew Research Center https://www. pewresearch.org/wp-content/uploads/sites/3/2011/10/ Multigenerational-Households-Finall.pdf (2011).

8. Ruppé, E., Andremont, A. \& Armand-Lefèvre, L. Travel Med. Infect. Dis. 21, 28-35 (2018).

9. Division of Labor Force Statistics. https://www.bls.gov/cps/ cpsaat18.pdf (2019)

10. Office of the Assistant Secretary for Planning and Evaluation. https://aspe.hhs.gov/system/files/pdf/264126/ CARB-National-Action-Plan-2020-2025.pdf (2020).

\section{Acknowledgements}

This research was supported in part by the Stuart B. Levy Center for Integrated Management of Antimicrobial Resistance at Tufts (Levy CIMAR), a collaboration of Tufts Medical Center and the Tufts University Office of the Vice Provost for Research (OVPR) Research and Scholarship Strategic Plan (RSSP).

\section{Author contributions}

M.L.N. and S.D. conceived of the idea. All authors developed the first draft, made substantial revisions, and read and approved the final manuscript.

\title{
The limits of acceptable political influence over the FDA
}

To the Editor - Extensive involvement of the White House in decision-making about the COVID-19 pandemic by the US Food and Drug Administration (FDA) has renewed attention to questions about the agency's independence ${ }^{1}$. Resultant calls to 'follow the science' and avoid 'politicizing' the FDA are rooted in legitimate concerns, but in the context of this pandemic, the relationship among science, values and politics has often been oversimplified. The FDA cannot make decisions on the basis of 
science alone ${ }^{2}$, and political considerations sometimes do have a role to play. Rather than redesigning the FDA as an independent agency, which risks sacrificing too much democratic accountability, it is preferable to protect the FDA's integrity by drawing a line between its broad policy decisions, which elected and appointed officials may appropriately influence, and decisions about specific applications before the agency, which should be shielded from such influence. Regardless of who occupies the White House, clarifying these issues remains important for the FDA's future.

Despite the extreme nature of the science-versus-politics dichotomy that has emerged in the wake of the FDA's response to COVID-19, agency decisions necessarily involve both scientific judgments and value judgments ${ }^{3}$. For example, FDA policymaking through regulations and guidance clarifies the types of scientific evidence the agency will rely on and how much it will demand, but it also illuminates how the agency intends to balance important tradeoffs in certainty, risk and benefit. The FDA's approval and authorization decisions for specific products similarly are informed by data about safety and efficacy, but the agency must also balance normative considerations about speed and certainty in light of disease severity and medical need.

The dual nature of the FDA's decision-making means that it cannot avoid political considerations, by which we mean governmental value judgments about competing goods and interests. A critical question, then, is whether these value judgments should be left to the FDA's career scientists or whether - and if so, to what extent - they legitimately may be influenced by the president's administration.

At present, both Congress and the executive branch exercise broad influence over the FDA, while the courts serve as a check on agency authority. Congress sets the agency's budget and establishes the legal parameters for agency decisions, while the president has the power to appoint (with confirmation by the Senate) and remove the FDA commissioner. In addition, the secretary of the Department of Health and Human Services (HHS), also a presidential appointee, has legal authority to override the FDA's rulemaking ${ }^{4}$ and approval decisions ${ }^{5}$, while the White House has authority to block agency regulations and guidance ${ }^{6}$.

Although these authorities have rarely been used, some critics worry that they leave the FDA too susceptible to the risk of political officials interfering with the agency's scientific decision-making for partisan ends ${ }^{3,7-9}$. Various proposals call for removing the FDA from HHS, increasing the agency's budgetary independence, stabilizing the commissioner's role to allow discharge only for cause, adopting cross-administration terms for the commissioner, moving to a multi-member board leadership model, and otherwise modeling the FDA on independent agencies such as the Social Security Administration. Under this approach, administrative law would still demand that the FDA consider public input through basic mechanisms such as the opportunity to comment on proposed rules and that it avoid 'arbitrary and capricious' decisions. The FDA would also remain subject to Congress's statutory oversight. Nonetheless, proposals for heightened independence would leave the FDA's career staff with expansive day-to-day responsibility to navigate the value judgments inherent in their policymaking and product-approval decisions.

Measures to protect the scientific components of the FDA's decision-making are justified. However, beyond constitutional attacks on agency independence that are gaining increased traction in the courts ${ }^{10}$, there are drawbacks that weigh against redesigning the FDA on this model. Most importantly, making the FDA less accountable to the president and appointed officials in the executive branch would make the agency less accountable to the public - and while there are other mechanisms of public accountability, they may be insufficient. Administrative law has traditionally offered only modest checks on agency authority, and although Congress can intervene, it is likely to do so only periodically, prospectively and at a high level of generality. Because Congress cannot impose new statutory requirements on the FDA without the agreement of both chambers and the president's signature, it is by design limited and cumbersome in its capacity to direct federal agencies, especially in the short term. By contrast, the more unitary executive branch can be nimbler in responding to unanticipated events, and the president can more easily direct agencies to achieve policy goals that reflect public priorities as expressed, for example, in presidential elections.

Reducing the FDA's responsiveness to the public by limiting its accountability to the executive branch is problematic, given the scope of reasonable disagreement about the role the FDA should play in drug development, how much regulatory burden is acceptable and how to balance speed and safety in approval decisions, among other value judgments. Advocates for FDA independence express confidence that "when values clash, an independent FDA will navigate the conflict with the nation's best interest in mind" ${ }^{3}$. Yet even the most well-intentioned FDA career scientist may have ideas about what is in the "nation's best interest" that are different from those of members of the public whose lives are affected by agency decisions. Moreover, especially if user fees are retained, an independent FDA might face greater risks of industry capture without a sufficient counterweight from other stakeholders. Overall, granting the party that controls the executive branch at the behest of the voting public some degree of influence over the FDA gives the American people an important means of influencing the value judgments that inevitably inform the FDA's decisions. Additional potential benefits to retaining the FDA's position within HHS include promoting policy alignment with other health-related executive agencies and facilitating collaboration between them ${ }^{11}$.

Critically, however, to accept that the administration should retain some ability to influence the FDA is not to suggest that administration officials should have unfettered discretion to intervene. First, even if they are not fully determined by scientific expertise, some FDA decisions can most effectively be made by those bearing such expertise. This distinction is often a matter of general versus specific decision-making. For example, it takes little technical know-how to express a legitimate preference between speed and certainty in getting new drugs to market. But when it comes to questions about trial design, manufacturing controls or post-market data collection, decisions about relevant tradeoffs benefit from deep, expert understanding of the issues. It is therefore imperative that career scientists retain civil-service and due-process protections meant to insulate them from being removed on the basis of perceived political obstruction or disloyalty ${ }^{12}$.

Second, even appointed officials with relevant scientific expertise, such as the FDA commissioner, are likely to have interests in advancing the political goals of the administration that appointed them, which in turn may bias their judgment or raise concerns about contradicting, mischaracterizing or rushing the science needed to inform decisions. Mitigating the risk of such bias requires limiting even expert political officials' involvement in specific agency decisions.

Taken together, these considerations suggest that an ideal arrangement would ensure that the FDA's decisions remain accountable to public values while limiting the extent to which inexpert or conflicted political actors can influence 
those decisions. The most promising way to satisfy these aims is through a division of labor: the FDA's career scientists should make unencumbered decisions about particular product applications, whereas elected and appointed officials should have a role in setting broader policies to guide those staff decisions. In all cases, application-level and policy-level decisions must align with the best available scientific evidence, incorporate necessary expertise, be transparent, and advance the FDA's public-health mission ${ }^{13}$.

A standard that precludes case-specific involvement for elected and appointed officials avoids the difficulty of specifying defensible exceptions. Contrast, for example, calls for the FDA commissioner to overrule a career scientist's decision to approve eteplirsen for Duchenne's muscular dystrophy ${ }^{14}$ against criticism of the HHS secretary's decision to overrule FDA staff about over-the-counter access to the contraceptive Plan $\mathrm{B}^{15}$. Yet a bright line leaving application-specific decisions to the FDA's career staff does not mean that they should be entirely insulated in their value judgments. If there is concern about how a particular product application was handled or general trends exhibited in case-specific decisions - perhaps requiring too much or too little evidence - administration officials can address those concerns prospectively by making broad policy changes.
What would this proposal look like in the context of COVID-19? It is within the legitimate purview of the White House, HHS and the FDA commissioner to weigh speed against certainty when it comes to the response to this pandemic. Depending on the broad policy approach ultimately selected, FDA career staff could be instructed to apply higher or lower evidentiary standards to emergency use authorization requests and marketing applications, without interference with their decisions about any particular product. When the FDA issues pandemic guidance, career staff should also abide by the administration's broad policy goals, but administration officials should defer to the expertise of career staff on which scientific requirements will best effectuate those goals. There can be no doubt that scientific expertise is essential, but political influence reflective of public values also has a legitimate role to play in shaping the FDA's value judgments.

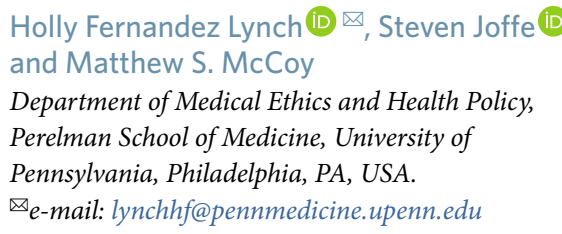

Published online: 18 January 2021

https://doi.org/10.1038/s41591-020-01200-w
References

1. Facher, L. STAT https://www.statnews.com/2020/08/27/trump has-launched-an-all-out-attack-on-the-fda-will-its-scientificintegrity-survive/ (27 August 2020).

2. Van Doren, P. CATO Institute https://www.cato.org/publications/ pandemics-policy/when-how-we-should-trust-science?queryID= Obb3779607a903f1bb72c4lflef4aaef (15 September 2020)

3. Adashi, E. Y., Rajan, R. S. \& Cohen, I. G. Science 364, 628-631 (2019).

4. US Department of Health and Human Services. https://www. hhs.gov/about/news/2020/09/20/hhs-statement-on-regulatoryprocess.html (2020)

5. 21 US Code $₫ 355$.

6. Vought, R.T. https://www.whitehouse.gov/wp-content/uploads/ 2019/04/M-19-14.pdf (11 April 2019)

7. Carpenter, D. Nature 485, 169-170 (2012).

8. Califf, R. et al. Washington Post https://www.washingtonpost. com/opinions/2020/09/29/former-fda-commissionerscoronavirus-vaccine-trump/ (29 September 2020).

9. Rubinstein Reiss, D. STAT https://www.statnews.com/2020/11/03/ should-fda-be-independent/ (2020).

10. Sunstein, C.R. \& Vermeule, A. New York Times https://www. nytimes.com/2020/09/15/opinion/us-government-constitution. html (15 September 2020).

11. Troy, D., Mendelson, D. \& Beier, D. Health Affairs Blog https:// www.healthaffairs.org/do/10.1377/hblog20190312.542301/full/ (19 March 2019).

12. Cancryn, A. \& Owermohle, S. POLITICO https://www.politico. com/news/2020/11/03/health-agencies-resist-trump-civilservice-executive-order-433892 (3 November 2020).

13. Sharfstein, J. Nature 585, 161 (2020).

14. Edwards, K. T. Food Drug Law J. 72, 406-450 (2017).

15. Baker, S. The Hill https://thehill.com/policy/healthcare/197825-se belius-overrules-fda-blocks-access-to-plan-b (7 December 2011).

Acknowledgements

We thank F.G. Miller, J. Darrow and I.G. Cohen for insight on the topics addressed in this article.

Competing interests

H.F.L. reports funding from The Greenwall Foundation. S.J. previously received research funding through the University of Pennsylvania Perelman School of Medicine from Pfizer. 